\title{
Implication of Anopheles funestus in malaria transmission in the city of Yaoundé, Cameroon
}

Landre Djamouko-Djonkam ${ }^{1,2}$, Diane Leslie Nkahe ${ }^{1,3}$, Edmond Kopya ${ }^{1,3}$, Abdou Talipouo ${ }^{1,3}$, Carmene Sandra Ngadjeu ${ }^{1,3}$, Patricia Doumbe-Belisse ${ }^{1,3}$, Roland Bamou ${ }^{1,2}$, Parfait Awono-Ambene ${ }^{1}$, Timoléon Tchuinkam ${ }^{2}$, Charles Sinclair Wondji ${ }^{4}$, and Christophe Antonio-Nkondjio ${ }^{1,4, *}$

${ }^{1}$ Laboratoire de Recherche sur le Paludisme, Organisation de Coordination Pour la Lutte Contre les Endémies en Afrique Centrale (OCEAC), P.O. Box 288, Yaoundé, Cameroon

${ }^{2}$ Vector Borne Diseases Laboratory of the Applied Biology and Ecology Research Unit (VBID-URBEA), Department of Animal Biology, Faculty of Sciences of the University of Dschang, P.O. Box 067, Dschang, Cameroon

${ }^{3}$ Faculty of Science, University of Yaoundé I, P.O. Box 337, Yaoundé, Cameroon

${ }^{4}$ Vector Biology, Liverpool School of Tropical Medicine, Pembroke Place, L3 5QA Liverpool, UK

Received 23 October 2019, Accepted 26 January 2020, Published online 12 February 2020

\begin{abstract}
The contribution of Anopheles funestus to malaria transmission in the urban environment is still not well documented. The present study assesses the implication of An. funestus in malaria transmission in two districts, Nsam and Mendong, in the city of Yaoundé. Adult mosquitoes were collected using Centers for Disease Control and Prevention miniature light traps (CDC-LT) and human landing catches from April 2017 to March 2018 and were identified morphologically to the species level. Those belonging to the Anopheles gambiae complex and to the Anopheles funestus group were further processed by PCR to identify members of each complex/group. Anopheline mosquitoes were analysed to determine their infection status using an enzyme-linked immunosorbent assay. Bioassays were conducted with 2-5-day-old female Anopheles funestus and An. gambiae s.l. to determine their susceptibility to permethrin, deltamethrin and dichlorodiphenyltrichloroethane (DDT). Six anopheline species were collected in the peri-urban district of Mendong: Anopheles gambiae, An. coluzzii, An. funestus, An. leesoni, An. ziemanni and An. marshallii; only four out of the six were recorded in Nsam. Of the two members of the Anopheles gambiae complex collected, An. coluzzii was the most prevalent. Anopheles coluzzii was the most abundant species in Nsam, while An. funestus was the most abundant in Mendong. Both Anopheles funestus and An. gambiae s.l. were found to be infected with human Plasmodium at both sites, and both were found to be resistant to DDT, permethrin, and deltamethrin. This study confirms the participation of An. funestus in malaria transmission in Yaoundé and highlights the need to also target this species for sustainable control of malaria transmission.
\end{abstract}

Key words: Malaria, Transmission, Anopheles funestus, Anopheles gambiae, Urban, Yaoundé, Cameroon.

Résumé - Implication d'Anopheles funestus dans la transmission du paludisme dans la ville de Yaoundé au Cameroun. La contribution d'Anopheles funestus à la transmission du paludisme en milieu urbain n'est pas encore bien documentée. La présente étude évalue l'implication d'An. funestus dans la transmission du paludisme dans la ville de Yaoundé. L'étude a été menée dans deux quartiers de la ville de Yaoundé, Nsam et Mendong. Des moustiques adultes ont été collectés à l'aide des pièges lumineux de type CDC et sur volontaires humains d'avril 2017 à mars 2018. Les moustiques appartenant au genre Anopheles ont été analysés afin de déterminer leur statut infectant grâce à la technique ELISA. Des bio-essais ont été effectués sur des femelles d'An. funestus et An. gambiae s.l. âgées de 2 à 5 jours afin de déterminer leur sensibilité à la perméthrine, la deltaméthrine et le dichlorodiphényltrichloroéthane (DDT). Six espèces d'anophèles ont été collectées dans le quartier périurbain de Mendong : An. gambiae, An. coluzzii, An. funestus, An. leesoni, An. ziemanni et An. marshallii ; seule les quatre premières ont été trouvées à Nsam. Des deux espèces du complexe An. gambiae retrouvées, An. coluzzii était la plus abondante. Anopheles gambiae s.l. était l'espèce prédominante à Nsam, tandis que An. funestus était la plus abondante à Mendong. Les deux espèces An. funestus et An. gambiae s.l. étaient infectées par des Plasmodium humains dans les deux sites, et se sont avérés résistantes au DDT, à la perméthrine et à la deltaméthrine. Cette étude confirme la participation d'An. funestus à la transmission du paludisme à Yaoundé et souligne la nécessité de cibler également cette espèce pour une lutte durable contre le paludisme.

*Corresponding author: antonio_nk@yahoo.fr

This is an Open Access article distributed under the terms of the Creative Commons Attribution License (https://creativecommons.org/licenses/by/4.0), which permits unrestricted use, distribution, and reproduction in any medium, provided the original work is properly cited. 


\section{Introduction}

Anthropogenic changes affecting the environment, such as large-scale unplanned urbanisation, are considered to have a major influence on vector-borne disease epidemiology [27, 29, 31]. In Cameroon, the city of Yaoundé is one of the largest in the country with a population of approximately three million inhabitants, and it has experienced intense modification of its natural environment throughout the past years. The rapid and spontaneous urbanisation in and around the city centre, with the absence of infrastructure for sanitation and surface water drainage, as well as the colonisation of lowland areas for urban agriculture or housing construction, has favoured the establishment of anophelines in an urban setting [5, 21]. In Cameroon, malaria is still a major public health problem affecting approximately $30 \%$ of the population annually $[51,64]$, and its prevention relies entirely on the use of insecticide-treated nets (ITNs) and/or long-lasting insecticidal nets (LLINs) [51]. However, overreliance on insecticides for both public health and agriculture over the past decades has contributed to the emergence and rapid expansion of pyrethroid resistance particularly in urban settings [5, 8, 9, 49]. In Yaoundé, Anopheles gambiae and An. coluzzii are the most important malaria vectors in the city centre $[56,66]$. Studies conducted at the periphery of the city of Yaoundé reported the presence of vectors such as An. moucheti, An. nili, and An. funestus, which contribute alongside An. gambiae s.l. to malaria transmission [2]. Anopheles funestus has always been reported in sympatry with An. gambiae in most rural settings in Cameroon [7, 10, 18]. In some places, this vector was found to perpetuate high infection rates surpassing those of An. gambiae, demonstrating the important epidemiological role that it can play [16]. Anopheles funestus has a close relationship to humans and usually displays high anthropophilic and endophilic behaviour [11, 20]. Similar to An. gambiae, high insecticide resistance has been reported for this vector population in Cameroon [38]. Resistant populations were found to overexpress different detoxification genes conferring resistance to organochlorines and pyrethroids [33, 39, 47]. The following examples highlight the increasing challenges for controlling these vector populations. To date, three species belonging to the An. funestus species group have been reported in Cameroon, including An. funestus, An. leesoni, and An. rivulorum [15]; however, only An. funestus is largely distributed across the country and has a major role in malaria transmission [2, 3, 11, 15]. Despite being recognised as a major malaria vector in Africa, the epidemiological role of An. funestus in the urban environment has only been explored with limited scope in both Cameroon and across Africa [14]. In the present study, the role of An. funestus in malaria transmission in the city of Yaoundé was investigated during a survey comparing malaria transmission dynamics between a central and a peri-urban district.

\section{Methods}

\section{Ethics approval and consent to participate}

The study was conducted under the ethical clearance No. 2016/11/832/CE/CNERSH/SP conferred by the Cameroon National Ethics Committee for Research on Human Health
(CNERSH) Ref. No. D30-172/L/MINSANTE/SG/DROS/ TMC on 4 April 2017. For human landing catches, all adult men who took part in the collection signed a written informed consent form before being enrolled in the study, as recommended by the validated protocol and were given free malaria prophylaxis.

\section{Study area}

The study was conducted in Yaoundé $\left(3^{\circ} 43^{\prime} 00^{\prime \prime}-3^{\circ} 58^{\prime} 00^{\prime \prime} \mathrm{N}\right.$ and $\left.11^{\circ} 24^{\prime} 30^{\prime \prime}-11^{\circ} 34^{\prime} 30^{\prime \prime} \mathrm{E}\right)$, the capital city of Cameroon. Yaoundé is a city covering a surface area of $304 \mathrm{~km}^{2}$ and situated $700 \mathrm{~m}$ above sea level. Its population is estimated to be approximately three million inhabitants. The city is drained by several permanent streams and is situated within the Congo-Guinean phytogeographic zone, characterised by vegetation dominated by Sterculiaceae and Ulmaceae [35]. The climate is of the equatorial type and comprises two rainy seasons extending from March to June and from September to November. The average rainfall in Yaoundé is estimated to be $1688 \mathrm{~mm} /$ year with an average annual temperature of $26{ }^{\circ} \mathrm{C}$. The average humidity is $80 \%$ and varies during the day between $35 \%$ and $98 \%$ [57]. The city is exposed to frequent humid winds blowing south-west to west or north to west [62].

Mosquito collections were conducted in the districts of Nsam and Mendong (Fig. 1). Nsam is situated in the city centre along the Mfoundi river, which provides excellent breeding opportunities for mosquitoes during the dry season. During the rainy season, breeding habitats are evenly distributed in the district; however, most of them are found in lowland areas. Mendong is a district situated at the periphery of the city along the Mefou river. The district is highly populated with construction in both highland and lowland areas (Table 1). Marshlands along the Mefou river are exploited for house construction and for the practice of market gardening during the dry season. The emergent vegetation in swamps and along the edges of the Mefou river provides ideal breeding opportunities for An. funestus, the predominant anopheline species in the district. The practice of agriculture in marshland during the dry season also promotes the presence of this species all year long.

\section{Adult mosquito collection}

Two collection methods targeting host-seeking mosquitoes Centers for Disease Control and Prevention miniature light traps (CDC-LT) (Model 512 6VDC John W. Hock) and human landing catches (HLCs) - were used from 07:00 pm to 06:00 am indoors and outdoors. Collections were undertaken during the months of April, June, August, October, and December in 2017 and March 2018. Collections using CDC light traps were conducted using 17-20 traps placed indoors and outdoors in a maximum of 12 different houses. In five houses, traps were placed both in and outdoors, whereas in the remaining houses, traps were placed exclusively indoors. Houses were chosen randomly and were separated from one another by a distance of approximately $100 \mathrm{~m}$. Mosquito collections were undertaken in each district over three consecutive nights each month to control for bias such as variation from rainfall and temperature (Table 2). CDC-LTs (Model 512 


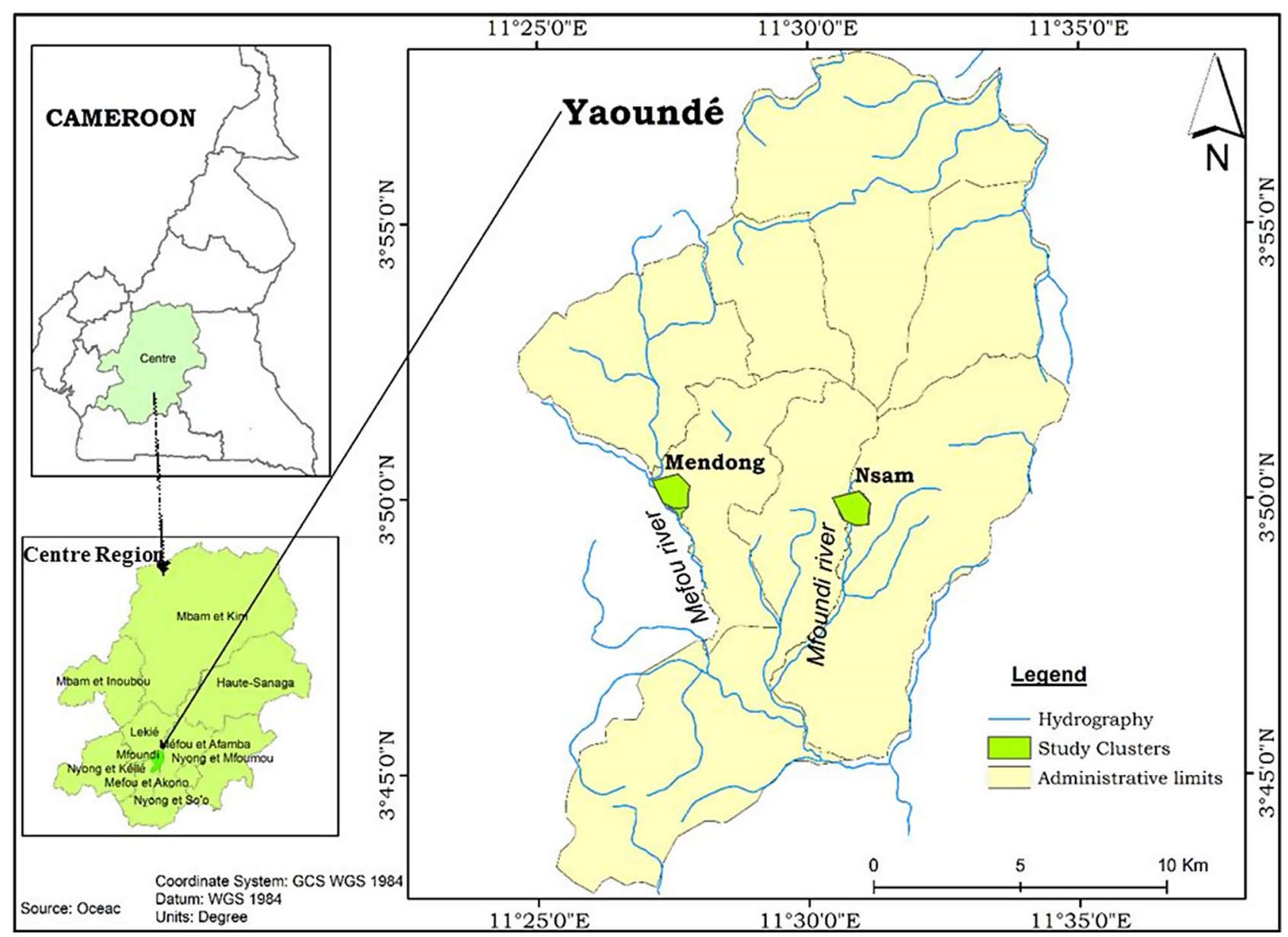

Figure 1. A map of Yaoundé showing the study sites of Mendong and Nsam.

Table 1. Characteristics of the study sites in Nsam and Mendong districts.

\begin{tabular}{lcc}
\hline Characteristic & Nsam & Mendong \\
\hline Situation & City centre & City periphery \\
Estimated population & 20,000 & 30,000 \\
Practice of urban agriculture & No & Yes \\
Presence of temporary breeding sites & ++ & +++ \\
Presence of permanent breeding sites & +++ & ++++ \\
LLIN ownership & $96 \%$ & $95 \%$ \\
Presence of cattle & No & Yes \\
Presence of other domestic animals & Yes & Yes \\
$\quad$ (chickens, pigs, goats, sheep, etc.) & & \\
Rearing of fish in pools & Yes & Yes \\
Rivers & Mfoundi & Mefou \\
\hline
\end{tabular}

++: low; +++: high; ++++: very high.

6VDC John W. Hock) were used as the main method to assess mosquito dynamics.

For human landing catches, collections were conducted in three houses (different from those used for CDC-LTs) in each district, both indoors and outdoors for one night. This collection technique was used to check the efficiency of CDC-LT collections. Once collected, mosquitoes were put into separate bags, and labelled according to the site, night and hour of collection.
Local field collectors conducted catches from 07:00 pm to 06:00 am. After giving their consent, they were followed throughout the study and were treated using an artemisininbased combination if they were detected as having malaria, as recommended by the Cameroon Ministry of Health.

\section{Mosquito processing}

Once collected, anophelines were separated from culicines using the morphological identification keys developed by Edwards [22]. Different anopheline species were also identified using morphological identification keys $[25,26]$. Each anopheline specimen was stored individually in a numbered tube containing desiccant, archived and kept in a freezer at $-20^{\circ} \mathrm{C}$.

Mosquitoes belonging to the An. gambiae complex were further processed by PCR [55] to distinguish An. coluzzii from An. gambiae, the two members of the complex found in Yaoundé. Molecular identification of members of the An. funestus group was conducted using the protocol developed by Koekemoer et al. [32]. DNA extracted from the wings and legs of the mosquitoes, according to the protocol developed by Livak and Schmittgen [36] was used for these analyses.

The head and thorax of female anophelines were tested for the presence of circumsporozoite protein (CSP) from Plasmodium falciparum using an enzyme-linked immunosorbent assay (ELISA), as described in Fontenille et al. [24]. 
Table 2. Monthly average temperature and precipitation/rainfall of 2017 in Yaoundé. ${ }^{a}$

\begin{tabular}{lcccccccccccc}
\hline & January & February & March & April & May & June & July & August & September & October & November & December \\
\hline Average $T\left({ }^{\circ} \mathrm{C}\right)$ & 26.5 & 27 & 27.5 & 27 & 25.5 & 25.5 & 24 & 23.5 & 24 & 24 & 25 & 26.5 \\
Min $T\left({ }^{\circ} \mathrm{C}\right)$ & 20 & 20 & 21 & 21 & 20 & 21 & 20 & 20 & 20 & 20 & 20 & 21 \\
Max $T\left({ }^{\circ} \mathrm{C}\right)$ & 33 & 34 & 34 & 33 & 31 & 30 & 28 & 27 & 28 & 28 & 30 & 32 \\
Precipitation $(\mathrm{mm})$ & 21 & 15 & 46 & 64 & 75 & 32 & 30 & 85 & 134 & 165 & 100 & 19 \\
\hline
\end{tabular}

${ }^{a}$ https://www.historique-meteo.net/afrique/cameroun/yaounde/2017/

$\mathrm{T}$ : temperature.

\section{Susceptibility to insecticides}

Susceptibility of An. gambiae and An. funestus to DDT (4\%), permethrin $(0.75 \%)$ and deltamethrin $(0.05 \%)$ was assessed using the WHO protocol [65]. Wild females of Anopheles funestus collected using HLC were kept alive to lay eggs. Larvae obtained from the eggs were reared to adults and used for bioassays. Wild females were identified to the species level. For Anopheles gambiae, larvae collected in temporary water collection in the field were reared to adults. Sampling was conducted from April to May 2017 during the short rainy season. Unfed Females of both species aged 2-5 days old were used to perform insecticide susceptibility tests. Batches of 20-25 mosquitoes per tube were exposed to impregnated papers for $1 \mathrm{~h}$. The number of mosquitoes knocked down by the insecticide was recorded every $10 \mathrm{~min}$ during exposure. After exposure, mosquitoes were fed with a $10 \%$ glucose solution, and the number of dead mosquitoes was recorded $24 \mathrm{~h}$ post-exposure. Tests using untreated papers were conducted as controls. The mortality rates were corrected using the Abbot formula [1] whenever the mortality rate of the controls was between $5 \%$ and $20 \%$. Susceptibility and resistance levels were assessed according to the World Health Organization criteria [63]. Female anophelines at the end of the tests were classified into three groups: insecticide resistant (if the mortality rate was $<80 \%$ ), insecticide tolerant (if the mortality rate was between $80 \%$ and $97 \%$ ), and insecticide susceptible (if the mortality rate was $>97 \%$ ).

To detect the presence of the $k d r$ alleles (L1014F and L1014S) conferring resistance to DDT and pyrethroids, DNA extracted from the wings and legs of a sub-sample of An. gambiae s.l. females was screened using a TaqMan assay [12]. The DNA was also used for species identification.

\section{Data analysis}

The biting rate (number of bites per person per night) was calculated as the number of mosquitoes caught in one night divided by the number of collectors. The infection rate was calculated as the number of infected anophelines divided by the total number processed. The entomological inoculation rate (EIR) was calculated by multiplying the infection rate by the human biting rate for one night, to obtain the daily EIR. The EIR for the CDC light traps was estimated as follows: $\mathrm{EIR}=1.605 \times($ No. of sporozoite positive ELISAs/No. of mosquitoes tested $) \times$ (No. of mosquitoes collected/No. of CDC light traps). The 1.605 represents the factor of overestimation of human landing catches compared to light traps.
The monthly EIR was calculated by multiplying the average daily EIR by the number of days in the month. The annual EIR was calculated by summing the monthly EIR for a year. The confidence interval was calculated using MedCalc statistical software, version 15.8 (MedCalc software bvba, Ostend, Belgium; https://www.medCalc.org; 2015). Statistical analyses were performed with SPSS Statistics for Windows, version 20 (SPSS Inc., Chicago, IL, USA) to compare percentages or averages. The level of significance of each test was set at $p=0.05$.

\section{Results \\ Species diversity}

A total of 7136 mosquitoes belonging to four genera were collected in both Mendong and Nsam. Of these, 5160 were collected in Nsam and 1976 in Mendong. Mosquitoes collected included Culex, Anopheles, Mansonia, and Aedes species at both sites. Culex species were the most abundantly represented with $88.1 \%$ and $58.7 \%$ of the total mosquitoes collected in Nsam and Mendong, respectively (Table 3). High anopheline species diversity was recorded in the peri-urban district of Mendong with six species collected, An. gambiae, An. coluzzii, An. funestus, An. leesoni, An. ziemanni, and An. marshallii, whereas only four were recorded in the urban district of Nsam (An. gambiae, An. coluzzii, An. funestus, An. leesoni). Anopheles gambiae emerged as the most abundant anopheline species in Nsam (10.3\% of the total), while An. funestus was the most abundant in Mendong (19\% of the total).

\section{Identification of members of the Anopheles gambiae complex and Anopheles funestus group}

A sub-sample of 107 An. gambiae s.l. from Nsam and 126 from Mendong randomly selected amongst mosquitoes collected at different periods were further processed to determine sibling species frequency in each district. From the analyses, An. coluzzii and An. gambiae were present at both sites. Anopheles coluzzii presented a frequency varying from $0 \%$ to $90.91 \%$ in Mendong and from $76.9 \%$ to $100 \%$ in Nsam (Table 4). In the An. funestus group, both An. funestus and An. leesoni were found at each site. Out of 200 specimens screened by PCR, 46 (23\%) were An. leesoni and 154 (77\%) An. funestus. The monthly variation in the frequency of the two species in Nsam and Mendong is presented in Table 4. 
Table 3. Mosquito species composition in Nsam and Mendong, Yaoundé, from April 2017 to March 2018.

\begin{tabular}{|c|c|c|c|c|c|c|c|c|}
\hline \multirow[t]{3}{*}{ Species } & \multicolumn{4}{|c|}{ Nsam } & \multicolumn{4}{|c|}{ Mendong } \\
\hline & CDC-LT & HLC & Total & $\overline{\%}$ & CDC-LT & HLC & Total & $\%$ \\
\hline & $N$ & $N$ & & & $N$ & $N$ & & \\
\hline Aedes sp. & 11 & 0 & 11 & 0.2 & 5 & 0 & 5 & 0.3 \\
\hline Culex sp. & 3414 & 1132 & 4546 & 88.1 & 847 & 313 & 1160 & 58.7 \\
\hline Mansonia sp. & 3 & 0 & 3 & 0.1 & 97 & 36 & 133 & 6.7 \\
\hline An. gambiae s.l. & 212 & 318 & 530 & 10.3 & 88 & 197 & 285 & 14.4 \\
\hline An. funestus & 50 & 20 & 70 & 1.4 & 309 & 66 & 375 & 19.0 \\
\hline An. ziemanni & 0 & 0 & 0 & 0.0 & 12 & 3 & 15 & 0.8 \\
\hline An. marshallii & 0 & 0 & 0 & 0.0 & 0 & 3 & 3 & 0.2 \\
\hline Total & 3690 & 1470 & 5160 & 100 & 1358 & 618 & 1976 & 100 \\
\hline
\end{tabular}

HLC: human landing catches; CDC-LT: CDC light traps; N: number of mosquitoes.

Table 4. Monthly variation of the composition of species in the An. gambiae complex and An. funestus group in Nsam and Mendong.

\begin{tabular}{|c|c|c|c|c|c|c|c|c|}
\hline Site & Species & $\begin{array}{c}\text { April } 17 \\
N(\%)\end{array}$ & $\begin{array}{c}\text { June } 17 \\
N(\%)\end{array}$ & $\begin{array}{c}\text { August } 17 \\
N(\%)\end{array}$ & $\begin{array}{c}\text { October } 17 \\
N(\%)\end{array}$ & $\begin{array}{c}\text { December } 17 \\
N(\%)\end{array}$ & $\begin{array}{c}\text { March } 18 \\
N(\%)\end{array}$ & $\begin{array}{c}\text { Total } \\
N(\%)\end{array}$ \\
\hline \multicolumn{9}{|c|}{ An. gambiae s.l. } \\
\hline \multirow[t]{2}{*}{ Mendong } & An. gambiae & $37(71.15)$ & $14(32.56)$ & $3(20)$ & $2(100)$ & $1(33.33)$ & $1(9.09)$ & $58(46)$ \\
\hline & An. coluzzii & $15(28.85)$ & $29(67.44)$ & $12(80)$ & $0(0)$ & $2(66.67)$ & $10(90.91)$ & $68(54)$ \\
\hline \multirow[t]{2}{*}{ Nsam } & An. gambiae & $6(23.08)$ & $2(6.67)$ & $3(14.29)$ & $0(0)$ & $2(18.18)$ & $0(0)$ & $13(12.1)$ \\
\hline & An. coluzzii & $20(76.92)$ & $28(93.33)$ & $18(85.71)$ & $8(100)$ & $9(81.82)$ & $11(100)$ & $94(87.9)$ \\
\hline \multicolumn{9}{|c|}{ An. funestus s.l. } \\
\hline \multirow[t]{2}{*}{ Mendong } & An. funestus & $90(86.54)$ & $12(70.59)$ & $2(40)$ & $3(100)$ & $2(50)$ & $3(33.33)$ & $112(78.9)$ \\
\hline & An. leesoni & $14(13.46)$ & $5(29.41)$ & $3(60)$ & $0(0)$ & $2(50)$ & $6(66.67)$ & $30(21.1)$ \\
\hline \multirow[t]{2}{*}{ Nsam } & An. funestus & $7(100)$ & $12(85.71)$ & $7(87.5)$ & $7(63.64)$ & $7(58.33)$ & $2(33.33)$ & $42(72.4)$ \\
\hline & An. leesoni & $0(0)$ & $2(14.29)$ & $1(12.5)$ & $4(33.36)$ & $5(41.67)$ & $4(66.67)$ & 16 (27.6) \\
\hline
\end{tabular}

\section{Dynamics of anopheline species collected using human landing catches}

In Mendong, An. gambiae s.l. and An. funestus were caught throughout the study period. The An. gambiae s.l. human biting rate (HBR) varied from 1.33 to 10.08 bites $/ \mathrm{man} / \mathrm{night}(\mathrm{b} / \mathrm{m} / \mathrm{n})$, while that of An. funestus varied from 0.33 to $14.5 \mathrm{~b} / \mathrm{m} / \mathrm{n}$. The peak of bites for An. gambiae was recorded in June 2017, and the lowest in October 2017, while the highest for An. funestus was recorded in April 2017 and the lowest in October 2017 (Fig. 2).

In Nsam, An. gambiae s.l. was collected throughout the study period using human landing catches, with the highest biting rate $(81 \mathrm{~b} / \mathrm{m} / \mathrm{n})$ recorded in June 2017. Anopheles funestus was less prevalent in the district; its highest biting rate was recorded in December $2017(2.17 \mathrm{~b} / \mathrm{m} / \mathrm{n})$.

\section{Dynamics of anopheline species collected using CDC light traps}

In Mendong, An. gambiae densities collected using CDCLTs varied from 0.04 in August to 0.85 mosquitoes/trap/night in April. Concerning An. funestus, its densities varied from 0.04 in August 2017 to 3.55 mosquitoes/trap/night in April 2017. In Nsam, the average density of An. gambiae s.l. varied from 0.03 in October 2017 to 2.2 mosquitoes/trap/night in June 2017; however, the density of An. funestus varied from 0.1 in August 2017 to 0.21 mosquito/trap/night in June 2017 (Fig. 3).
The Pearson correlation coefficient, used to assess the relationship between CDC-LT and HLC, indicated no significant correlation in the sampling efficiency between CDC-LT and HLC when all mosquitoes were considered in Mendong ( $r=0.47, p=0.09$ ) whereas a significant correlation was found in Nsam $(r=0.67, p=0.03)$.

\section{Night biting cycle of anophelines collected with HLC}

In Nsam, An. gambiae s.l. was recorded as biting all night long. However, there was a peak of bites occurring between 2 am and 3 am indoors $(0.75 \mathrm{~b} / \mathrm{m} / \mathrm{h})$ and between 2 am and $4 \mathrm{am}(1.45 \mathrm{~b} / \mathrm{m} / \mathrm{h})$ outdoors. Anopheles funestus was also recorded biting predominantly outdoors during the second part of the night.

In Mendong, Anopheles gambiae was predominant outdoors, particularly during the second part of the night. Its peak of biting was recorded between midnight and 1 am outdoors $(1.19 \mathrm{~b} / \mathrm{m} / \mathrm{h})$ and 2 am and 3 am indoors $(1.19 \mathrm{~b} / \mathrm{m} / \mathrm{h})$. Anopheles funestus biting densities increased from $0 \mathrm{~b} / \mathrm{m} / \mathrm{h}$ to $0.6 \mathrm{~b} / \mathrm{m} / \mathrm{h}$ between midnight and $1 \mathrm{am}$, and then decreased during the second part of the night (Fig. 4).

\section{Sporozoite infection rate}

Out of 1020 mosquitoes processed using ELISA, 39 were found to be infected: 25 collected using CDC-LTs, distributed 


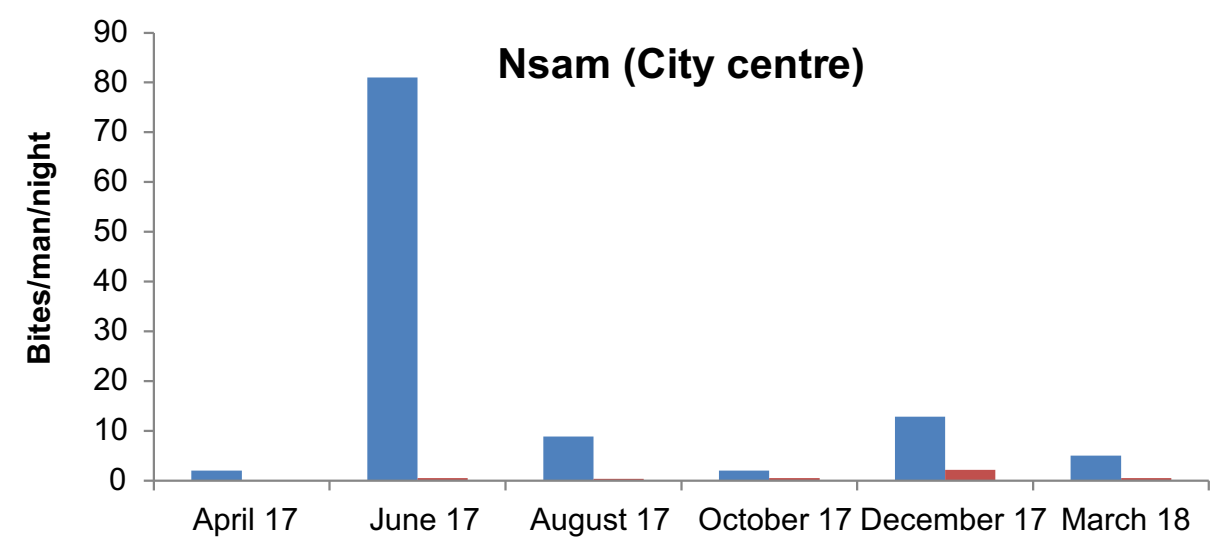

An. gambiae sl $\square$ An. funestus



Figure 2. Monthly variation of biting densities of An. gambiae s.l. and An. funestus collected using HLC in Mendong and Nsam from April 2017 to March 2018.

as follows: 10 An. gambiae s.l. (6 out of 210 at Nsam and 4 out of 84 at Mendong) and 15 An. funestus (1 out of 44 at Nsam and 14 out of 296 at Mendong). Similarly, 14 infected mosquitoes were collected by HLC and this included $10 \mathrm{An}$. gambiae s.l. (1 out of 157 at Nsam and 9 out of 145 at Mendong) and 4 An. funestus ( 1 out of 20 at Nsam and 3 out of 64 at Mendong) (Table 5). Two An. leesoni specimens within the An. funestus group were recorded as infected in Mendong. Of the 20 An. gambiae s.l. recorded infected, 10 were An. coluzzii (four in Mendong and six in Nsam) and 10 An. gambiae (nine in Mendong and one in Nsam). Most infection cases were due to Plasmodium falciparum (88\%), and the remaining cases $(12 \%)$ were infections due to Plasmodium ovale, $P$. malariae, or $P$. vivax. Infected mosquitoes were detected almost every month at both sites. The infection rate was significantly different between the two sites $(p<0.015)$.

\section{Entomological inoculation rate (EIR)}

Both collections from CDC-LTs and human landing collections were used for EIR estimation. The CDC-LT entomological inoculation rate was estimated at 15.64 infected mosquito bites/man/year (ib/m/yr) at Mendong, and $6.14 \mathrm{ib} / \mathrm{m} / \mathrm{yr}$ at Nsam. The entomological inoculation rate calculated using HLC was $106.83 \mathrm{ib} / \mathrm{m} / \mathrm{yr}$ at Mendong and $9.78 \mathrm{ib} / \mathrm{m} / \mathrm{yr}$ at Nsam (Table 6). Transmission was not recorded during the months of August, October, and December in Mendong, and in August and December at Nsam. Infected mosquitoes collected with CDC-LTs were more regularly observed in Nsam than in Mendong (Fig. 5A and B). The contribution of both An. funestus and An. gambiae to the annual entomological inoculation rate according to the different collection methods in each study site is presented in Table 6.

\section{Susceptibility of An. gambiae and An. funestus to DDT, permethrin, and deltamethrin}

A total of 829 An. gambiae and 200 An. funestus females were exposed to permethrin, deltamethrin, and DDT. Anopheles funestus collected at Mendong were resistant to deltamethrin, permethrin and DDT [33.33\% (95\% CI [21.6-49.2]), 65\% (95\% CI [48.3-86.4]) and 76\% (95\% CI [53.4-104.3]) mortality rate, respectively]. Concerning An. gambiae females, they were resistant to DDT, deltamethrin, and permethrin at both 




An. gambiae $\square$ An. funestus



$\square$ An. gambiae $\square$ An. funestus $\square$ An. ziemannii $\square$ An. marshallii

Figure 3. Monthly variation of anopheline densities collected using CDC-LT in Mendong and Nsam from April 2017 to March 2018.

sites with a mortality rate varying from $0 \%$ to $62.5 \%$ (Table 7 ). Of the 60 An. gambiae s.l. screened to detect the presence of the $k d r$ allele, 49 were detected as carrying the west African $k d r$ allele L1014F, whereas three were detected as carrying the east African $k d r$ allele L1014S. $K d r$ allele frequency in the population was estimated at $44 \%$.

\section{Discussion}

The study objective was to assess the implication of An. funestus in malaria transmission in the city of Yaoundé by comparing malaria transmission patterns between an urban and a peri-urban district of the city. High malaria transmission carried by both An. funestus and An. gambiae s.l. was recorded.
The involvement of An. funestus in malaria transmission alongside An. gambiae contrasted with previous records [23, 46], as well as with the findings from the city of Douala where transmission is mainly sustained by An. gambiae s.l. [6, 48]. Anopheles funestus has rarely been reported to transmit malaria in urban settings [34, 50]. The typical breeding habitats of An. funestus are permanent or semi-permanent water collections with emergent vegetation [26]. Its presence in the city of Yaoundé may result from the presence of marshland covered with emerging vegetation along the Mfoundi and Mefou rivers [21]. Anopheles funestus is widely distributed across the country [3] and in most rural settings where it has been reported, it may sustain very high levels of malaria transmission $[2,7,16,61]$. It was also found to bite predominantly indoors, whereas most An. gambiae s.l. bites were recorded outdoors. 




An funestus Outdoor An. gambiae Outdoor

An. funestus indoor $\longrightarrow$ An. gambiae indoor

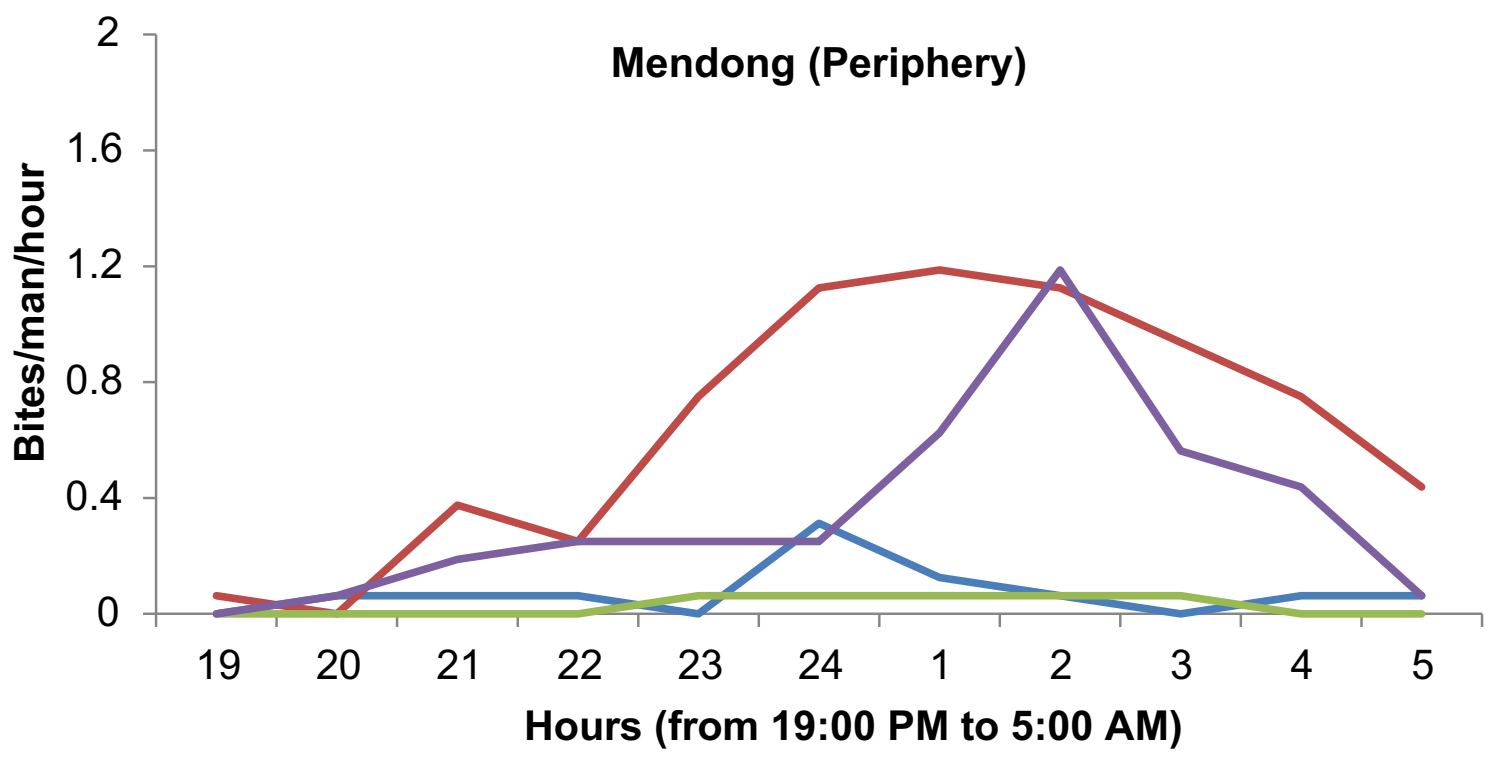

An funestus Outdoor An. gambiae Outdoor

An. funestus indoor $\longrightarrow$ An. gambiae indoor

Figure 4. Night biting cycle of An. gambiae s.l. and An. funestus in Mendong and Nsam.

Both species were recorded to bite frequently during the second part of the night, with An. gambiae s.l. recorded biting extensively even after $5 \mathrm{am}$. This may improve its capacity to maintain residual malaria transmission since after $5 \mathrm{am}$, most people are out of their bed nets and active (studying for students, cleaning the house, or preparing for the day).

Increased transmission of malaria due to changes in mosquito biting behaviour has been reported in previous studies [40]. High species diversity was recorded in the district of Mendong with six species collected and just four in Nsam.
The diversity of species might result from the high variety of breeding habitats in Mendong compared to Nsam with the presence of puddles, lakes, rivers, and swamps, which could be excellent habitats for a variety of mosquito species [2, 4, 11, 21]. Seasonal fluctuations in the biting densities of An. funestus, particularly in Mendong, were recorded with a sharp increase at the onset of the rainy season. The abundance of An. funestus during this period could be due to the extension of swamps associated with growing vegetation at their edges, which increased breeding opportunities for An. funestus. 
Table 5. Plasmodium falciparum infection rate of mosquitoes collected using HLCs and CDC-LTs in Nsam and Mendong.

\begin{tabular}{|c|c|c|c|c|c|c|c|c|c|c|c|c|}
\hline \multirow[t]{3}{*}{ Species } & \multicolumn{6}{|c|}{ Mendong } & \multicolumn{6}{|c|}{ Nsam } \\
\hline & \multicolumn{3}{|c|}{ HLC } & \multicolumn{3}{|c|}{ CDC-LT } & \multicolumn{3}{|c|}{ HLC } & \multicolumn{3}{|c|}{ CDC-LT } \\
\hline & $N$ & Infected & IR $(95 \%$ CI) & $N$ & Infected & IR $(95 \%$ CI) & $N$ & Infected & IR $(95 \%$ CI) & $N$ & Infected & IR $(95 \%$ CI) \\
\hline An. gambiae s.l. & 145 & 9 & $0.06(0.03-0.12)$ & 84 & 4 & $0.05(0.01-0.12)$ & 157 & 1 & $0.01(0-0.03)$ & 210 & 6 & $0.03(0.01-0.06)$ \\
\hline An. funestus s.l. & 64 & 3 & $0.05(0.01-0.14)$ & 296 & 14 & $0.05(0.03-0.08)$ & 20 & 1 & $0.05(0-0.28)$ & 44 & 1 & $0.02(0-0.13)$ \\
\hline Total & 209 & 12 & $0.06(0.03-0.1)$ & 380 & 18 & $0.05(0.03-0.07)$ & 177 & 2 & $0.011(0-0.04)$ & 254 & 7 & $0.03(0.01-0.06)$ \\
\hline Overall* & 589 & 30 & $0.05(0.03-0.07)$ & & & & 431 & 9 & $0.02(0.01-0.04)$ & & & \\
\hline
\end{tabular}

* Sum of CDC-LT and HLC per site; CDC-LT: CDC light traps; HLCs: human landing catches; IR: infection rate; 95\% CI: 95\% confidence interval.

Table 6. Estimation of the entomological inoculation rate (EIR) using CDC light traps or human landing catches in Nsam and Mendong.

\begin{tabular}{|c|c|c|c|c|}
\hline \multirow[t]{2}{*}{$\mathrm{CDC}$} & \multicolumn{2}{|c|}{ Mendong } & \multicolumn{2}{|c|}{ Nsam } \\
\hline & Annual EIR* & $\%$ & Annual EIR* & $\%$ \\
\hline An. gambiae s.l. & 3.43 & 21.93 & 5.16 & 84.05 \\
\hline An. funestus s.l. & 12.21 & 78.07 & 0.98 & 15.95 \\
\hline Total & 15.64 & 100 & 6.14 & 100 \\
\hline \multicolumn{5}{|l|}{ HLC } \\
\hline An. gambiae s.l. & 72.59 & 67.95 & 4.61 & 47.18 \\
\hline An. funestus s.l. & 34.24 & 32.05 & 5.17 & 52.82 \\
\hline Total & 106.83 & 100 & 9.78 & 100 \\
\hline
\end{tabular}

* Infective bites/man/year.

Similar observations were reported elsewhere [17]. Anopheles gambiae s.l. was present all year long at both sites; however, there were high densities recorded during the short rainy season (April-June).

Both An. gambiae s.l. and An. funestus were resistant to permethrin, deltamethrin, and DDT. These findings were consistent with studies conducted across the country reporting rapid evolution of insecticide resistance in these vector populations [9, 38]. The profile of susceptibility in An. gambiae s.l. populations to insecticides was similar between the two districts and may suggest similar selective pressure at both sites. In Cameroon, the rapid evolution of insecticide resistance in vector populations is thought to result from selective pressure exerted by the frequent use of treated nets, sprays, and coils in households and pesticide use in agriculture [13, 45]. Although pesticides are commonly used in urban farming, the limited area used for agriculture in Mendong might decrease the impact of selective pressure due to pesticides. It is still not known whether insecticide resistance intensity is similar between the two sites, and this deserves further investigation. Currently, only overexpression of detoxification genes is known to confer resistance to organochlorine and pyrethroids in An. funestus populations in Cameroon [38, 52, 53, 67, 68], whereas both target-site mutations and metabolic mechanisms have been reported in An. gambiae s.l. populations from Cameroon [9, 44, 58].

Anopheles funestus belongs to a group of nine morphologically similar species [14], which can be identified by molecular assays [15, 32]. Three of these species, An. funestus,
An. rivulorum, and An. leesoni, have been reported in Cameroon [15, 41]. Molecular identification indicated the presence of An. funestus and An. leesoni in both districts. This is the first time An. leesoni has been reported in the city of Yaoundé. Interestingly, two An. leesoni were also found to be infected. Although An. leesoni is frequently reported across the continent, it is considered to have a limited role in malaria transmission [19, 26]. However, it is becoming important to confirm its role as a vector of malaria through dissection of the salivary glands.

Within members of the An. gambiae complex, both An. gambiae and An. coluzzii were recorded. Anopheles coluzzii was the predominant species at both sites, representing $87.85 \%$ and $53.97 \%$ of the total species in Nsam and Mendong, respectively. These data were in accordance with previous studies reporting a heterogeneous distribution of these species in the city of Yaoundé $[28,59]$.

A high malaria transmission rate was recorded in both districts and likely suggests an elevated malaria transmission risk in both the centre and the city periphery. According to Robert et al. [54], the annual entomological inoculation rate in sub-Saharan Africa could be as high as seven in city centres, 45.8 in peri-urban areas, and 167.7 in rural areas. Transmission levels recorded during this study in the city of Yaoundé were far above these values as well as those previously recorded [23, 60]. Additionally, such high levels likely point to the negative influence of unplanned urbanisation on malaria transmission and are consistent with studies conducted in other major subSaharan African cities [6, 30, 34, 37, 42, 43, 48, 50, 54, 69]. 



B



Months

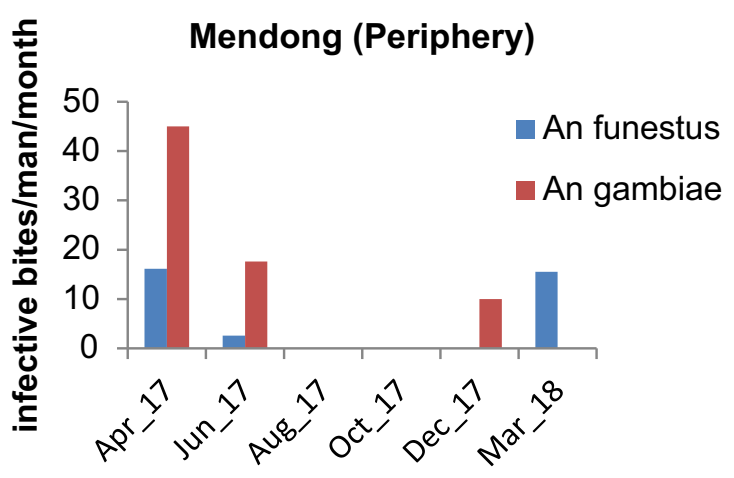

Months

Figure 5. Malaria transmission pattern in Mendong and Nsam from April 2017 to March 2018: (A) monthly EIR using CDC light traps; (B) monthly variation of standard EIR using human landing catches.

Table 7. Mortality rates for An. gambiae s.l. and An. funestus field populations after exposure to $4 \%$ DDT, $0.75 \%$ permethrin, and $0.05 \%$ deltamethrin in Mendong and Nsam.

\begin{tabular}{|c|c|c|c|c|c|c|c|}
\hline \multirow[t]{3}{*}{ Site } & \multirow[t]{3}{*}{ Insecticide } & \multicolumn{6}{|c|}{ Species } \\
\hline & & \multicolumn{3}{|c|}{ An. gambiae s.l. } & \multicolumn{3}{|c|}{ An. funestus } \\
\hline & & $N$ & Mortality (\%) & $95 \% \mathrm{CI}$ & $N$ & Mortality (\%) & $95 \% \mathrm{CI}$ \\
\hline \multirow{4}{*}{ Mendong } & $0.05 \%$ deltamethrin & 236 & 62.5 & $40.3-60.7$ & 75 & 33.33 & $21.6-49.2$ \\
\hline & $0.75 \%$ permethrin & 193 & 13.89 & $42.2-60.8$ & 75 & 65 & $48.3-86.4$ \\
\hline & $4 \% \mathrm{DDT}$ & 100 & 2 & $0.2-7.2$ & 50 & 76 & $53.8-104.3$ \\
\hline & $0.05 \%$ deltamethrin & 100 & 3 & $0.62-8.8$ & & & \\
\hline \multirow{2}{*}{ Nsam } & $0.75 \%$ permethrin & 100 & 0 & $0-3.7$ & & & \\
\hline & $4 \%$ DDT & 100 & 0 & $0-3.7$ & & & \\
\hline
\end{tabular}

DDT: dichlorodiphenyltrichloroethane; N: number of mosquitoes tested; $95 \%$ CI: $95 \%$ confidence interval.

\section{Conclusion}

The present study highlights challenges affecting malaria control in the urban environment and confirms the important epidemiological role played by An. funestus in the urban environment. In the case of Yaoundé, where vectors display high pyrethroid resistance, different species take part in malaria transmission, and hotspot areas are well identified. The implementation of an integrated control approach combining larvicidal or environmental management by draining urban swamps, with improvements in urban planning, and promotion of the use of treated nets could be indicated for the control and elimination of malaria vectors in Yaoundé.

\section{Competing interests}

The authors declare that they have no competing interests. 


\section{Funding}

This work received financial support from a Wellcome Trust Senior Fellowship in Public Health and Tropical Medicine (202687/Z/16/Z) to CAN. The funding body did not have any role in the experimental design, collection of data, analysis, and interpretation of data, or in the writing of the manuscript.

\section{Author contributions}

Conceived and designed the study protocol: CAN; participated in field and laboratory activities: DDL, NDL, KE, TA, NCS, DBP, BR, AAP, CAN; critically revised the manuscript: CSW, TT, AAP; interpreted, analysed data and wrote the paper: CAN, DDL with contributions from other authors. All the authors read and approved the final version.

\section{References}

1. Abbott W. 1925. A method of computing the effectiveness of an insecticide. Journal of American Mosquito control Association, 3(2), 302-303.

2. Antonio-Nkondjio C, Awono-Ambene H, Toto J, Meunier J, Zebaze-Kemleu S, Nyambam R. 2002. High malaria transmission intensity in sub-urban area of Yaoundé: the capital city of Cameroon. Journal of Medical Entomology, 39(2), 350-355.

3. Antonio-Nkondjio C, Kerah C, Simard F, Awono-Ambene H, Mouhamadou C, Tchuinkam T. 2006. Complexity of malaria vectorial system in Cameroon: contribution of secondary vectors to malaria transmission. Journal of Medical Entomology, 43(6), 1215-1221.

4. Antonio-Nkondjio C, Ndo C, Costantini C, Awono-Ambene P, Fontenille D, Simard F. 2009. Distribution and larval habitat characterization of Anopheles moucheti, Anopheles nili, and other malaria vectors in river networks of southern Cameroon. Acta Tropica, 112(3), 270-276.

5. Antonio-Nkondjio C, Fossog $\mathrm{B}$, Ndo C, Djantio B, Zébazé-Togouet S, Awono-Ambene $\mathrm{P}$, Costantini C, Wondji C, Ranson H. 2011. Anopheles gambiae distribution and insecticide resistance in the cities of Douala and Yaounde (Cameroon): influence of urban agriculture and pollution. Malaria Journal, 10, 154.

6. Antonio-Nkondjio C, Defo-Talom B, Tagne-Fotso R, Tene-Fossog B, Ndo C, Lehman L. 2012. High mosquito burden and malaria transmission in a district of the city of Douala, Cameroon. BMC Infectious Diseases, 12, 275.

7. Antonio-Nkondjio C, Demanou M, Etang J, Bouchite B. 2013. Impact of cyfluthrin (Solfac EW050) impregnated bed nets on malaria transmission in the city of Mbandjock: lessons for the nationwide distribution of long-lasting insecticidal nets (LLINs) in Cameroon. Parasites \& Vectors, 6(1), 10.

8. Antonio-Nkondjio C, Tene Fossog B, Kopya E, Poumachu Y, Menze-Djantio B, Ndo C, Tchuinkam T, Awono-Ambene H, Wondji C. 2015. Rapid evolution of pyrethroid resistance prevalence in Anopheles gambiae populations from the cities of Douala and Yaoundé (Cameroon). Malaria Journal, 14, 155.

9. Antonio-Nkondjio C, Sonhafouo-Chiana N, Ngadjeu CS, Doumbe-Belisse P, Talipouo A, Djamouko-Djonkam L, Kopya E, Bamou R, Awono-Ambene P, Wondji CS. 2017. Review of the evolution of insecticide resistance in main malaria vectors in Cameroon from 1990 to 2017. Parasites \& Vectors, 10(1), 472.
10. Awono-Ambene P, Antonio-Nkondjio C, Toto J, Ndo C, Etang J, Fontenille D, Simard F. 2009. Epidemological importance of the Anopheles nili group of malaria vectors in equatorial villages of Cameroon, Central Africa. Sciences et Medécine d'Afrique, 1, 13-20.

11. Ayala D, Carlo C, Ose K, Kamdem G, Antonio-Nkondjio C, Agbor J. 2009. Habitat suitability and ecological niche profile of major malaria vectors in Cameroon. Malaria Journal, 8, 307.

12. Bass C, Nikou D, Donnelly M, Williamson M, Ranson H, Ball A, Vontas J, Field L. 2007. Detection of knockdown resistance (kdr) mutations in Anopheles gambiae: a comparison of two new high-throughput assays with existing methods. Malaria Journal, 6, 111.

13. Bowen H. 2013. Impact of a mass media campaign on bed net use in Cameroon. Malaria Journal, 12(1), 36.

14. Coetzee M, Fontenille D. 2004. Advances in the study of Anopheles funestus, a major vector of malaria in Africa. Insect Molecular Biology, 34, 599-605.

15. Cohuet A, Simard F, Toto J, Kengne P, Coetzee M. 2003. Species identification within the Anopheles funestus group of malaria vectors in Cameroon and evidence for a new species. American Journal of Tropical Medicine and Hygiene, 69, 200-205.

16. Cohuet A, Dia I, Simard F, Raymond M, Fontenille D. 2004. Population structure of the malaria vector Anopheles funestus in Senegal based on microsatellite and cytogenetic data. Insect Molecular Biology, 13(3), 251-258.

17. Cohuet A, Simard F, Wondji C, Antonio-Nkondjio C, Awono-Ambene H, Fontenille D. 2004. High malaria transmission intensity due to Anopheles funestus (Diptera: Culicidae) in a village of Savannah-Forest transmission area in Cameroon. Journal of Medical Entomology, 41, 901-905.

18. Cohuet A, Dia I, Simard F, Raymond M, Rousset F, AntonioNkondjio C, Awono-Ambene P, Wondji C, Fontenille D. 2005. Gene flow between chromosomal forms of the malaria vector Anopheles funestus in Cameroon Central Africa, and its relevance in malaria fighting. Genetics, 169, 301-311.

19. Derua YA, Alifrangis M, Magesa SM, Kisinza WN, Simonsen PE. 2015. Sibling species of the Anopheles funestus group, and their infection with malaria and lymphatic filarial parasites, in archived and newly collected specimens from northeastern Tanzania. Malaria Journal, 14(1), 104.

20. Dia I, Diallo D, Duchemin J, Ba Y, Konate L, Costantini C, Diallo M. 2005. Comparisons of human-landing catches and odor-baited entry traps for sampling malaria vectors in Senegal. Journal of Medical Entomology, 42, 104-109.

21. Djamouko-Djonkam L, Mounchili-Ndam S, Kala-Chouakeu N, Nana-Ndjangwo SM, Kopya E, Sonhafouo-Chiana N, Talipouo A, Ngadjeu CS, Doumbe-Belisse P, Bamou R, Toto JC, Tchuinkam T, Wondji CS, Antonio-Nkondjio C. 2019. Spatial distribution of Anopheles gambiae sensu lato larvae in the urban environment of Yaoundé, Cameroon. Infectious Diseases of Poverty, 8(1), 84.

22. Edwards F. 1941. Mosquitoes of the Ethiopian Region. III. Culicine adults and pupae. London: Bulletin of the British Museum (Natural History). 499 p.

23. Fondjo E, Robert V, Le Goff G, Toto J, Carnevale P. 1992. Urban malaria transmission in Yaounde (Cameroon). 2. Entomologic study in 2 semi urban districts. Bulletin de la Société de Pathologie Exotique, 85, 57-63.

24. Fontenille D, Meunier J, Nkondjio C, Tchuinkam T. 2001. Use of circumsporozoite protein enzyme-linked immunosorbent assay compared with microscopic examination of salivary glands for calculation of malaria infectivity rates in mosquitoes (Diptera: Culicidae) from Cameroon. Journal of Medical Entomology, 38, 451-454. 
25. Gillies M, Coetzee M. 1987. A supplement to the Anophelinae of Africa south of the Sahara (Afrotropical region). South Africa: Pub. South Africa Institut for Medical Research Johannesburg. $143 \mathrm{p}$.

26. Gillies M, De Meillon B. 1968. The Anophelinae of Africa South of the Sahara. South Africa: South Africa Institute of Medical Research Johannesburg. 343 p.

27. Hay S, Guerra C, Tatem A, Atkinson P, Snow R. 2005. Urbanization, malaria transmission and disease burden in Africa. Nature Reviews Microbiology, 3, 81-90.

28. Kamdem C, Fossog B, Simard F, Etouna J, Ndo C, Kengne P. 2012. Anthropogenic habitat disturbance and ecological divergence between incipient species of the malaria mosquito Anopheles gambiae. PLoS One, 7(6), e39453.

29. Keiser J, Utzinger J, Caldas de Castro M, Smith T, Tanner M, Singer B. 2004. Urbanization in sub-saharan Africa and implication for malaria control. American Journal of Tropical Medicine and Hygiene, 71, 118-127.

30. Klinkenberg E, McCall P, Wilson M, Akoto A, Amerasinghe F, Bates I, Verhoeff F, Barnish G, Donnelly M. 2006. Urban malaria and anaemia: a cross-sectional survey of two cities in Ghana. Tropical Medicine and International Health, 11, 578-588.

31. Klinkenberg E, McCall P, Wilson M, Amerasinghe F, Donnelly M. 2008. Impact of urban agriculture on malaria vectors in Accra, Ghana. Malaria Journal, 7, 151.

32. Koekemoer L, Kamau L, Hunt R, Coetzee M. 2002. A cocktail polymerase chain reaction assay to identify members of the Anopheles funestus (Diptera: Culicidae) group. American Journal of Tropical Medicine and Hygiene, 66, 804-811.

33. Kwiatkowska R, Platt N, Poupardin R, Irving H, Dabire R, Mitchell S. 2013. Dissecting the mechanisms responsible for the multiple insecticide resistance phenotype in Anopheles gambiae s.s., M form, from Vallee du Kou, Burkina Faso. Gene, 519(1), 98-106.

34. Labbo R, Fandeur T, Jeanne I, Czeher C, Williams E, Arzika I, Soumana A, Lazoumar R, Duchemin J-B. 2016. Ecology of urban malaria vectors in Niamey, Republic of Niger. Malaria Journal, 15(1), 314.

35. Letouzey R. 1985. Notice de la carte phytogéographique du Cameroun au 1/500 000. Toulouse, France: Institut de la carte internationale de la végétation. p. 63-94.

36. Livak KJ, Schmittgen TD. 2001. Analysis of relative gene expression data using real-time quantitative pcr and the $2-\Delta \Delta$ CT Method. Methods, 25(4), 402-408.

37. Mathanga DP, Tembo AK, Mzilahowa $T$, Bauleni A, Mtimaukenena K, Taylor TE, Valim C, Walker ED, Wilson ML. 2016. Patterns and determinants of malaria risk in urban and peri-urban areas of Blantyre, Malawi. Malaria Journal, 15(1), 590.

38. Menze BD, Riveron JM, Ibrahim SS, Irving H, AntonioNkondjio C, Awono-Ambene PH. 2016. Multiple insecticide resistance in the malaria vector Anopheles funestus from northern Cameroon is mediated by metabolic resistance alongside potential target site insensitivity mutations. PLoS One, 11 (10), e0163261.

39. Mitchell S, Stevenson B, Mueller P, Wilding C, Egyir-Yawson A, Field S, Hemingway J, Paine M, Ranson H, Donnelly M. 2012. Identification and validation of a gene causing crossresistance between insecticide classes in Anopheles gambiae from Ghana. Proceedings of the National Academy of Sciences USA, 109, 6147-6152.

40. Moiroux N, Boussari O, Djenontin A, Damien G, Cottrell G, Henry M-C, Guis H, Corbel V. 2012. Dry season determinants of malaria disease and net use in Benin, West Africa. PLoS One, 7(1), e30558.
41. Mouchet J, Cavalie P, Callies J, Marticou H. 1961. L'irritabilité vis a vis du DDT d'Anopheles gambiae et d'A. funestus dans le Nord-Cameroun. Rivista di Malariologia, 40, 191-217.

42. Mourou J, Coffinet T, Jarjaval F, Pradines B, Amalvict R, Rogier C, Kombila M, Pages F. 2010. Malaria transmission and insecticide resistance of Anopheles gambiae in Libreville and Port-Gentil, Gabon. Malaria Journal, 9, 321.

43. Mourou J-R, Coffinet T, Jarjaval F, Cotteaux C, Pradines E, Godefroy L, Kombila M, Pages F. 2012. Malaria transmission in Libreville: results of a one year survey. Malaria Journal, 11(1), 40.

44. Muller P, Chouaibou M, Pignatelli P, Etang J, Walker E, Donnelly M. 2007. Pyrethroid tolerance is associated with elevated expression of antioxidants and agricultural practice in Anopheles arabiensis sampled from an area of cotton fields in northern Cameroon. Molecular Ecology, 17(4), 1145-1155.

45. Ndo C, Menze-Djantio B, Antonio-Nkondjio C. 2011. Awareness, attitudes and prevention of malaria in the cities of Douala and Yaoudé (Cameroon). Parasites and Vectors, 4(1), 181.

46. Nimpaye H, Van Der Kolk M, Fontenille D, Boudin C. 2001. Etude entomologique dans le quartier central "Dakar". Bulletin de Liaison et de Documentation - OCEAC, 34, 11-14.

47. Nkya T, Akhouayri I, Poupardin R, Batengana B, Mosha F, Magesa S. 2014. Insecticide resistance mechanisms associated with different environments in the malaria vector Anopheles gambiae: a case study in Tanzania. Malaria Journal, 13, 28.

48. Ntonga Akono P, Tonga C, Mbida Mbida J, Ngo Hondt O, Awono-Ambene H, Ndo C. 2015. Anopheles gambiae, vecteur majeur du paludisme à Logbessou, zone péri-urbaine de Douala (Cameroun). Bulletin de la Société de Pathologie Exotique, 108(5), 360-368.

49. Nwane P, Etang J, Chouaibou M, Toto J, Koffi A, Mimpfoundi R, Simard F. 2013. Multiple insecticide resistance mechanisms in Anopheles gambiae sl populations from Cameroon, Central Africa. Parasites \& Vectors, 107(1), 8-14.

50. Oyewole I, Awolola T. 2006. Impact of urbanization on bionomics and distribution of malaria vectors in Lagos, southwestern Nigeria. Journal of Vector Borne Diseases, 43, 173-178.

51. PNLP. 2012. Plan stratégique national de lutte contre le paludisme 2011-2015. Rapport Minsante Cameroun, Yaoundé. p. 1-82.

52. Riveron JM, Ibrahim SS, Chanda E, Mzilahowa T, Cuamba N, Irving $\mathrm{H}$, Barnes KG, Ndula M, Wondji CS. 2014. The highly polymorphic CYP6M7 cytochrome P450 gene partners with the directionally selected CYP6P9a and CYP6P9b genes to expand the pyrethroid resistance front in the malaria vector Anopheles funestus in Africa. BMC Genomics, 15, 817.

53. Riveron JM, Chiumia M, Menze BD, Barnes KG, Irving H, Ibrahim SS, Weedall GD, Mzilahowa T, Wondji CS. 2015. Rise of multiple insecticide resistance in Anopheles funestus in Malawi: a major concern for malaria vector control. Malaria Journal, 14, 344.

54. Robert V, Macintyre K, Keating J, Trape J, Duchemin J, Warren M, Beier J. 2003. Malaria transmission in urban sub-saharan Africa. American Journal of Tropical Medicine and Hygiene, 68, 169-176.

55. Santolamazza F, Calzetta M, Etang J. 2008. Distribution of knock-down resistance mutations in Anopheles gambiae molecular forms in west and west-central Africa. Malaria Journal, $7(1), 74$.

56. Simard F, Ayala D, Kamdem G, Pombi M, Etouna J, Ose K, Fotsing J, Fontenille D, Besansky N, Costantini C. 2009. Ecological niche partitioning between Anopheles gambiae molecular forms in Cameroon: the ecological side of speciation. BMC Ecology, 9, 17. 
57. Suchel J. 1987. Les climats du Cameroun, tome III. Thèse Université de Saint Etienne France: Saint Etienne, 1186 p.

58. Tene Fossog B, Poupardin R, Costantini C, Awono-Ambene H, Wondji C, Ranson H, Antonio-Nkondjio C. 2013. Resistance to DDT in an urban setting: common mechanisms implicated in both $\mathrm{M}$ and $\mathrm{S}$ forms of Anopheles gambiae in the city of Yaoundé Cameroon. PLoS One, 8(4), e61408.

59. Tene Fossog B, Ayala D, Acevedo P, Kengne P, Ngomo Abeso Mebuy I, Makanga B. 2015. habitat segregation and ecological character displacement in cryptic African malaria mosquitoes. Evolutionary Applications, 8(4), 326-345.

60. Van der Kolk M, Etti Tebo A, Nimpaye H, Ngo Ndombol D, Sauerwein R, Eling W. 2003. Transmission of Plasmodium falciparum in urban Yaoundé Cameroon is seasonal and agedependent. Transactions of the Royal Society of Tropical Medicine and Hygiene, 97, 375-379.

61. Wanji S, Tanke T, Atanga N, Ajonina C, Tendongfor N, Fontenille D. 2003. Anopheles species of the mount Cameroon region: biting habits, feeding behaviour ant entomological inoculation rates. Tropical Medicine and International Health, 8, 643-649.

62. Wethé J, Radoux M, Tanawa E. 2003. Assainissement des eaux usées et risques socio - sanitaires et environnementaux en zones d'habitat planifié de Yaoundé (Cameroun). VertigO - La Revue Électronique en Sciences de L'environnement, 4(1), 4741.

63. WHO. 1998. Test procedures for insecticide resistance monitoring in malaria Vectors. Bio-efficacy and Persistence of insecticides on treated surfaces. WHO/MAL/98.12. Report of the WHO Informal Consultation. Geneva: World Health Organization. $43 \mathrm{p}$.

64. WHO. 2012. WHO global malaria programme World Malaria Report 2012. Switzerland: WHO Press. 259 p.

65. WHO. 2013. Recommendations for achieving universal coverage with long-lasting insecticidal nets in malaria control. Switzerland: World Health Organization. 4 p.

66. Wondji C, Frederic S, Petrarca V, Etang J, Santolamazza F, Della Torre A, Fontenille D. 2005. Species and populations of the Anopheles gambiae complex in Cameroon with special emphasis on chromosomal and molecular forms of Anopheles gambiae s.s. Journal of Medical Entomology, 42(6), 998-1005.

67. Wondji CS, Irving H, Morgan J, Lobo NF, Collins FH, Hunt RH, Coetzee M, Hemingway J, Ranson H. 2009. Two duplicated P450 genes are associated with pyrethroid resistance in Anopheles funestus, a major malaria vector. Genome Research, 19(3), 452-459.

68. Wondji CS, Dabire RK, Tukur Z, Irving H, Djouaka R, Morgan JC. 2011. Identification and distribution of a GABA receptor mutation conferring dieldrin resistance in the malaria vector Anopheles funestus in Africa. Insect Biochemistry and Molecular Biology, 41(7), 484-491.

69. Yadouleton A, N'Guessan R, Allagbe H, Asidi A, Boko M, Osse R, Padonou G, Kinde G, Akogbeto M. 2010. The impact of the expansion of urban vegetable farming on malaria transmission in major cities of Benin. Parasites \& Vectors, $3(1), 118$.

Cite this article as: Djamouko-Djonkam L, Nkahe DL, Kopya E, Talipouo A, Ngadjeu CS, Doumbe-Belisse P, Bamou R, Awono-Ambene HP, Tchuinkam T, Wondji CS \& Antonio-Nkondjio C. 2020. Implication of Anopheles funestus in malaria transmission in the city of Yaoundé, Cameroon. Parasite 27, 10.

- PARASTE

An international open-access, peer-reviewed, online journal publishing high quality papers on all aspects of human and animal parasitology

Reviews, articles and short notes may be submitted. Fields include, but are not limited to: general, medical and veterinary parasitology; morphology, including ultrastructure; parasite systematics, including entomology, acarology, helminthology and protistology, and molecular analyses; molecular biology and biochemistry; immunology of parasitic diseases; host-parasite relationships; ecology and life history of parasites; epidemiology; therapeutics; new diagnostic tools.

All papers in Parasite are published in English. Manuscripts should have a broad interest and must not have been published or submitted elsewhere. No limit is imposed on the length of manuscripts.

Parasite (open-access) continues Parasite (print and online editions, 1994-2012) and Annales de Parasitologie Humaine et Comparée (1923-1993) and is the official journal of the Société Française de Parasitologie. 